\title{
SATISFACTION WITH PREGNANCY AND DELIVERY SERVICES: THE QUALITY OF MATERNITY CARE SERVICES AS EXPERIENCED BY WOMEN.
}

Autors: Josefina Goberna-Tricas ${ }^{\mathrm{a}}$ PhD, Full Professor, Midwife, Sociologist; Mª Rosa Banús-Giménez, ${ }^{\text {a,b }}$ Associate Professor, Midwife; Alicia Palacio-Tauste, ${ }^{\text {a,b }}$ Associate Professor, Midwife; Sara LinaresSancho, ${ }^{\mathrm{b}}$ Midwife.
a.- Catalonian School of Midwifery, School of Nursing. University of Barcelona.
b.- Women's Sexual and Reproductive Health Programme. Institute Català de la Salut. Spain. 


\section{Introduction}

Pregnancy and delivery constitute a powerful experience for women (Vandenvusse, 1999; Lavender et al., 2004; Larkin et al., 2009), one that is characterized by a particular sense of fragility and vulnerability. Among those activities geared toward caring for human life, attending to the birth process has been important since the origins of our species (Collière, 1982). Until a few decades ago such care was left exclusively to women, and the attitude taken was almost always expectant rather than interventionist. However, social and economic changes during the twentieth century, along with improved knowledge and health technology, saw the emergence and development of a more technological approach to the birth process (Kitzinger, 1992; Barlow, 1994; Smeenk and ten-Have, 2003).

Although mankind has always used tools and technology to modify and control nature, in the past any improvements tended to occur sporadically and in an unplanned way; progress, if it occurred, consisted in subsequent steps to be taken (Jonas, 1995). Modern technology, however, offers just the opposite: nowadays, any step forward in technology or science does not lead to a new point of equilibrium, but rather, should it prove successful, provides a reason to push forward in all possible directions (Mckinlay, 1982). Ongoing research thus becomes a goal in itself. Each technical innovation is rapidly disseminated throughout the scientific community and technological developments quickly become widespread. Therefore, progress is no longer an option arising out of technology that we can then use as we please, but rather becomes an inherent driving force itself, one which goes beyond human desires (Kornelsen, 2005; Wade and Halligan, 2004). This new role for technology can be clearly seen in all areas of life, although particularly in the field of health sciences (Marquez and Meneu, 2003).

Prior to the second half of the twentieth century, women in Spain gave birth at home and were cared for by midwives (García-Martínez, 2008). However, the birth process slowly moved into the hospital (Cabero, 2003). Technological developments have also left their mark on ante-natal care: ultrasound examinations and amniocentesis have greatly increased medical capabilities in terms of the prenatal diagnosis of various congenital defects (Carrera et al., 2001; Strauss, 2002).

In Spain a technologized childbirth care system evolved in the second half of the twentieth century, whereas in other areas such as the Scandinavian countries or Netherlands a deinstitutionalized care model, attended mainly by midwives, began to gain ground (Wiegers, 2009). There is a third group of countries which chose an 
intermediate model that combines institutionalized maternity care with a lower level of medicalization; the United Kingdom is one of the countries where this approach is used (Thompson, 2010).

Since the end of the twentieth century, social movements in defence of a less interventionist maternity care model have emerged in some Western countries. In 1993 the Changing Childbirth report was published in the UK. In Spain the reaction against excessive institutionalization took longer to develop, but recently users' associations have begun to call for a professional care model that involves lower levels of medical and technological intervention. The matter has sparked debate at institutional level and the Spanish Ombudsman's Report of 2006 reflected the demand, calling for the implementation of a protocol for natural non-medicalized maternity care. Around the same time, the National Health Service Quality Plan drawn up by the Ministry of Health proposes as its main objective the provision of a more personalized health care model based on patients' needs and expectations (Ministerio de Sanidad y Consumo, 2006). And in 2007 the Women's Health Observatory published its Strategy Document for normal childbirth care.

At the present time there is institutional interest in consolidating humanized maternity care. At the same time, they should not neglect the important role of technology: women who receive maternity care have been socialized in a technologized environment, and in most cases, the use and mastery of the new technologies forms part of their everyday lives (Maroto-Navarro, et al., 2004). Here the role of health professionals takes on a new dimension: in addition to mastering the technical procedures, they must also pay special attention to the human dimension and to developing their relational and communicative skills (Lavender et al., 1999; Kukla, 2009; Jimenez et al., 2010). For that, now the studies aim to understand and improve the quality of maternity services, by obtaining not only information on outcomes indicators, such as mortality or morbidity, but also information about women's views and experiences with structure and process indicators of care (Janssen and Wiegers, 2006; Declerq et al., 2006; Redshaw, 2008).

In this study we investigate the opinions of women regarding the quality of maternity care received. We hope to identify the factors that are perceived as essential to quality care, and also to establish whether health care technology increases satisfaction or whether it actually interferes with the construction of personal satisfaction in the process of care during pregnancy and delivery.

\section{The study (Material and methods)}


This study received a special research grant from the Bellvitge Campus at the University of Barcelona in 2006. In 2008, the study has broadened its objectives thanks to a grant from the Ministry of Science and Innovation to study the different ethical paradigms in greater depth and to investigate the models of care that promote the principle of autonomy among pregnant women.

\section{Design}

This research used a qualitative perspective as this offers better opportunities of accessing the participants' understanding of the particular life process. Qualitative methodology acknowledges the person and his/her context as basic elements in reaching an understanding of reality, the reasons behind the facts, and the meaning people give to their own actions. In this regard, it emphasizes the understanding of human behaviour described by Max Weber as Verstehen, which aims to understand the intention of actions from the person's point of view. Therefore, empathy is a way to sympathy (Von Wrigth, 1987).

\section{Method}

The present analysis used a theoretical-methodological perspective based on the comprehension of the knowledge generated by experience itself, one in which the researcher is involved in the research process regarding the experiences described. The researcher observes, describes, understands and interprets the experiences and the meanings assigned to the experiences reported at a specific moment. Thus, the researcher observes through other people's points of view (Taylor and Bogdan, 1998; Hammersley and Atkinson, 2001).

The theoretical-methodological perspective of phenomenology was used in this research project as it is a method which focuses on people's experiences in relation to a specific phenomenon, in this case, the maternity care services, and the interpretation of these experiences. According to Van Maanen the link between data and theoretical knowledge is achieved through reflection (Van Maanen, 1990).

\section{Sample}

The study sample was chosen from the women attending the postnatal groups run by the Sexual and Reproductive Health Care Program (PASSIR), of the Catalan Health Institute. The sample varied widely in terms of the type of childbirth, age, and social class. Women who met the inclusion criteria were invited to take part by the 
midwives. Prior to conducting the study informed consent was obtained from each participant, it being explained to them that confidentiality would be ensured at all times.

In order to respect the wishes of the women who declined to participate, the focus groups were carried out at different times from the postnatal groups and were led by the principal investigator who had no health care contact with the participants in the study.

\section{Technique}

A focused-interview method was used to gather information. The focus group technique is based on "a carefully planned discussion designed to obtain perceptions on a defined area of interest in a permissive, non-threatening environment" (Krueger, 2000). The advantage of using focus groups is that a large amount of data is produced. However, the results cannot be generalized statistically as the tool used is not quantitative and, therefore, does not seek to obtain statistical validity. This does not mean that the results cannot be generalized as such.

Five focus groups were held between May 2006 and July 2007. Three of these took place in the primary care centre (PCC) in Cornellà, part of the metropolitan area of Barcelona (Spain), while the other two focus groups were held in PCCs in the towns of Centelles and Vic, both of which are situated in the region of Osona, a rural area in the province of Barcelona (Spain).

In total, thirty-one women took part, (Tables 1-5). The duration of each session ranged from $85-126$ minutes.

\section{Analysis}

All the group sessions were recorded and transcribed. Data were then presented in the form of a narrative text from which the emerging themes were identified; these were then coded (Weber, 1990).

After a literal transcription of the focus group session the content was analysed in order to systematize and study the information. The content analysis involved three stages. The initial pre-analysis stage included a transcription of the focus group, along with the design and definition of the project's basis in order to examine the data and analyse the content. Secondly, the codification stage involved transforming the global data into useful data. In order to transcribe the data it was necessary to fragment the text, and thus recording units were established and all the elements were catalogued. Finally, the categorisation stage organised and classified the obtained units according to the differentiation criteria. Each group was organised in terms of units with equivalent meanings (Bardin, 1986; Kippendroff, 1980). 
In order to achieve and ensure quality criteria we considered what Guba et al., 1989, terms trustworthiness, which is based on the satisfactory attainment of four constructs: credibility, through the explanation of the data collection process; transferability, through the description of the type of sample; dependability, which refers to the stability of data collection; and confirmability, in which the research team's position is clearly explained such that another researcher could confirm the study using the same data

In order to protect anonymity all participants were identified with a randomly assigned number within each of the focus groups, which were labelled as follows: C1, $\mathrm{C} 2$ and $\mathrm{V} 1, \mathrm{~V} 2$.

\section{Results}

Reading and analysing the participants' discussion enabled us to obtain the research descriptors. Three categories were established as a result of the discussion and were then analysed in a meaning map. From the point of view of users, quality of care is a complex concept in which a number of independent core features can be identified.

\section{The components of quality care}

Participants' perceptions of the quality of care are based on three main elements. The first is safety: the hospital and its technological facilities, and the technical expertise of health professionals, confer a sensation of protection. The other two main pillars of quality of care are the human dimension of the relationship between the carers and the patient, and finally the structural aspects that determine the context in which the heath care is provided.

\section{Safety.}

The sensation of safety is expressed in two fundamental aspects; health technology and professional expertise.

\subsection{The role of technology}

Most of the women saw health technology in a positive light, and being aware of technological advances helped them feel safe and reassured. Statements such as the following are highly significant in this regard: 
"I think it's really good, the hospital is well equipped; the machines and all that." $(\mathrm{V} 2,1)$

However, this opinion was not shared by all the women. A small proportion of participants did not feel there was such a need for technology; these women asked for less medicalized care and saw childbirth as a physiological process in which technology was not necessary:

“...I was able to have a shower, then go for a walk, and finally around 10 a.m. I said, right, now I'm ready to push, and the midwife told me they would come and fetch me. I was already dilated $10 \mathrm{~cm} . "(\mathrm{~V} 1,5)$

During delivery they accept that it is necessary to monitor the foetus and understand that this offers greater control over foetal well-being:

"I think that (the monitor) reassures you. They said to me: 'Here we go! Now you'll have a contraction', and that way you have time to prepare yourself and you're not caught by surprise. I think it does reassure you, you know that things are going OK, everything's fine at the moment. Although you don't want to, and however far on you are, you're still scared that something will go wrong... so that way you feel a bit more relaxed." (V2, 3)

The reassurance which technology offers in terms of foetal well-being does not prevent them from recognizing that it often causes discomfort or pain:

"I also had it, after they gave me the epidural, and then they told me to push when I had a contraction, to see if the right position was being taken up, but the monitor bothered me, and I even remember that at one point the midwife was pressing on me and it hurt, because she was pressing with that disc and of course, it hurt". $(\mathrm{V} 1,1)$

The perception and evaluation of pain during childbirth presents significant individual variations, especially with regard to the need for anaesthetic. For some women the pain of childbirth may be a gratifying experience. One of the most interesting responses was: 
"It was a gratifying pain, I knew why it was hurting and it did hurt, but the pain was gratifying" $(\mathrm{C} 1,4)$

But most respondents consider that the experience of pain is unnecessary, and that the most sensible thing is to use the modern technology available in order to prevent it. Anaesthetic is the ideal tool to improve the experience of childbirth. One respondent made the following comment:

"I asked for the epidural anaesthetic the moment I went in: having a baby is one thing, and being a masochist is another" $(\mathrm{C} 2,1)$

During the health care to pregnancy, most women in the study asked for more ultrasound examinations. Being able to see the foetus gives them a stronger sense of its existence; it makes the pregnancy more objective and this produces a feeling of well-being and reassurance. This is illustrated by statements such as:

"I would have liked more ultrasounds, because one every trimester, I don't know, even if everything is OK... It would have reassured me if they'd done another ultrasound." (V2, 3)

Some of the statements reveal that ultrasound examinations are at times seen like a consumer product, almost like a luxury, which reassures them psychologically and gives them a permanent reminder of the child they are carrying inside. For this reason, some of the women attended a private clinic in order to have further ultrasound examinations.

"I think the number of ultrasounds is OK, but for the mother's peace of mind, not out of need, it would be good to have more ultrasounds, more than anything for the mother's peace of mind ... Me, for example, I went to a private gynaecologist and he did one in four dimensions and I have to say that I was really happy, reassured, and also because it was what I wanted and it meant a lot to me." $(\mathrm{C} 2,1)$

\subsection{Technical expertise}

Healthcare professionals offer knowledge and skills that can ensure high-quality obstetric care. The women recognise, and do not question, the professional skills of 
doctors and midwives. Indeed, they value the technical skills of the professionals responsible for their care, as is illustrated by the following statement:

"They're professionals, and they know what they have to do at all times." (V2, 4)

The presence of a qualified professional is perceived as indispensable. One of the women in the study expressed her absolute need for a qualified professional who could oversee the whole process:

"I would have suffered terribly if I hadn't had a professional with me... it was really important for me, and for my little girl, that there was somebody, you know, a professional...l would have been really scared without a doctor or midwife at my side." $(\mathrm{V} 1,5)$

None of the women reported deficiencies in the level of professionalism or technical ability of the health personnel responsible for their care; indeed, they considered that the gynaecologists, midwives and nurses were all highly skilled professionals. One of the women expressed her satisfaction with the work of a midwife, who had avoided the need for an episiotomy:

"I had a lovely midwife, who said to me: 'I'm not going to do an episiotomy, we're going to see if she comes out on her own', and with her own hand she helped things along, and the fact is that I only needed one stitch." $(\mathrm{C} 1,2)$

\section{The relational aspect of care}

When asked to evaluate the quality of care received the women in the study made a clear distinction between technical and interpersonal skills; in some cases they were satisfied with the healthcare side but not with the personal treatment:

"The midwife who saw me, she knew what she was doing but she wasn't at all friendly... l'd give her ten out of ten for how she managed the birth of my daughter, I've got no complaints, but she wasn't at all friendly." (V1, 3) 
Even when they were satisfied with the care received as a whole, the women distinguished between professional/technical skills and the human aspect of the relationship, and regard these two aspects as complementary features of overall care:

“I'm very happy with how they've looked after me, and the people I've seen have been very nice." $(\mathrm{C} 1,1)$

The women consider that, during the delivery, they should be treated with 'tender loving care' as they are going through a difficult time in which they need the moral support of health professionals:

"I think that health staff should show a bit of TLC because they're dealing with ill people. When you're giving birth you're not ill, but you have pain like when you are ill, and what you want is a bit of TLC." $(\mathrm{C} 2,6)$

There is also a clear demand for a more personal approach: the women want health professionals to be not only technically skilled but also capable of respecting their autonomy and values as women in order to foster the trust and empathy that are seen as essential features of an effective therapeutic relationship. The women in our study want professionals to show a caring attitude and empathy. The principles of character or virtue give pride of place to the virtuous character, (Aristotle, 1994; Beauchamp and Childress, 1994), and 'tender loving care' is what the women studied most appreciate and want from health professionals. In this regard some professionals met the women's expectations while others fell short. The former is illustrated by comments made by some of the mothers who felt very satisfied with the care they received:

"For me everything was really good, it was like being at home; they treated me as if they'd known me all their lives, I guess I didn't think they'd treat me so well, so very well, they were always at my side... they were always checking up on me and I never once felt alone or disoriented, with that feeling of not knowing what was going to happen to you; I was really fine and I feel very happy." $(\mathrm{V} 1,2)$

In contrast, there is one case in which the dissatisfaction with the personal relationship is very clear: 
"I'm very happy, except with one midwife who said something that really hurt me. She asked me if I was in pain and I said yes, and then she said: OK, well I'll leave you to it and I'll be right back. Maybe it's because they so young....but what she said went right through me. I started crying, there on my own without my husband, without anything...I felt awful, helpless, there on my own..." $(C 1,4)$

At the time of the birth the bond between mother and baby is a key feature of a woman's entry into motherhood, and it is precisely at this point that the women in the study identified a lack of empathy on the part of professionals. Monitoring the newborn's vital signs becomes the main objective of health professionals, who do not always take into account the mother's feelings:

"When the baby was born they put him on top of me for a few seconds so I could kiss him a bit, but then I didn't get him back for two hours. They'd just stitched me up and then I was in the recovery room for quite a long time, and then they brought me the baby. And of course, later I had problems with breastfeeding, so I rang a pro-breastfeeding association for advice and they said that one of the reasons might be that they didn't bring me the baby until later." $(C 1,5)$

This aspect acquires greater relevance in those cases where the woman had a caesarean or where the newborn required special care, situations in which the women felt they'd been forgotten. This is illustrated in the comments of a mother who asked for the greatest possible contact between mother and baby following a premature delivery:

"They took mine away as well, I didn't see him and that's frustrating, even if he's premature. Once they've had a look at him, then if he's OK they should leave him with you, whereas they hardly let me see him." (C2, 2)

\section{Structural obstacles to achieving individualized care}

However, the satisfaction with the care received does not only depend on the personality of - and relationship with - the health professionals involved, but also on 
the fact that these relationships take place in an organization which may foster or hinder the quality of care and satisfaction with it.

\subsection{The hospital environment}

The hospital environment gives women a greater sense of security from a technological point of view; they feel reassured and put their trust in all the technology on offer in the hospital setting:

"You go in feeling scared, you're nervous, really afraid, but once you're in hospital you think, OK now l'm safe." (V1, 2)

"I think it's really good, the hospital is well equipped; the machines and all that." $(\mathrm{V} 2,1)$

However, the other side of the coin is that the hospital setting constitutes a hostile and depersonalized environment in which it is not possible to maintain an individualized relationship based on trust. This is partly because staff work shifts and the monitoring is often done by someone different; furthermore, when it's time to give birth the woman has to begin a new relationship with different professionals and this makes it difficult to develop a sense of trust:

"I'm happy. The only thing I would say is that the hospital, in my view, is very impersonal, very impersonal, because you're not always seen by the same person, and the way they treat you is nothing like the way they treat you here in the health centre." $(C 1,4)$

\section{2. - Primary care centres}

With the exception of certain high-risk pregnancies a pregnant woman will be monitored in a primary care setting. Therefore, the relationship with the midwife who monitors the pregnancy develops in a climate of greater proximity and mutual trust, and it is thus much easier to establish. Appointments with the midwife in the primary care setting are perceived as taking place in a more intimate and friendlier environment, one in which pregnant women feel they can put their trust.

"During the pregnancy, if you have any doubts, anything, you just call the midwife and she sees you straightaway, and if she sees that 
you're nervous or worried she'll immediately say, come on, let's talk about it." $(\mathrm{V} 1,6)$

\subsection{The demand on services}

Another of the aspects that affects quality of care is the demand on healthcare services, something which can be seen both during the prenatal care and in the delivery room.

"Personally, I would have liked to have had longer appointments... when you go for an ultrasound and you see that there are three women ahead of you and three behind it makes you think there should be more doctors." (V2, 1)

Having a midwife all to yourself for the delivery is seen as a privilege which the women recognize will not always be possible. In this regard the following statement is of interest:

"I had a midwife with me all the time, and I was lucky that I didn't have to share her." $(\mathrm{C} 1,4)$

\section{Discussion}

As a group, mothers-to-be are aware of technology and it tends to produce two opposing effects in them. On the one hand they feel satisfied with healthcare technology and view it as a source of security; the knowledge that they are in a hospital environment with modern technological facilities is comforting if there are complications. These impressions coincide with the results reported by other authors (Johnson et al., 1992; Williams, 2006). The possibility of controlling pain by applying epidural anaesthetic is an important source of reassurance for mothers-to-be; epidural anaesthetic is widely used in Spain as the method of choice for pain relief during childbirth (Johanson et al., 2002; Sabaté et al., 2006). The literature notes that the perception of what constitutes normal maternity care depends too on the messages the women have received from their family and friends, (Maroto-Navarro, 2004; Young, 2009) and the social imaginary in Spanish considers pain relief via spinal techniques as a clear sign of quality of care. Though previous studies suggest that pain in childbirth is a variable that affects the satisfaction and perception of the quality of the care received, 
(Fawcett et al., 1992; Green, 1993; Slade et al., 1993; Fowles, 1998; Lavender et al., 1999) other studies report that if women are able to develop self-control and selfconfidence to control the pain their satisfaction with the overall experience will be greater (Waldenstrom, 1996; Petra et al., 2004; Belle-Brown et al., 2009). To this end, continuous support during the care, information and joint deliberation in decisionmaking is essential, as is continuity of care throughout the process (Lavender et al., 1999; Belle-Brown et al., 2009).

In our study only a small number of women preferred physiological management of childbirth. These women actively exercised the principle of autonomy and opted to be attended in hospitals that applied the care protocols for normal childbirth.

It is this dependence on technology which forms the other side of the coin. Western women at the beginning of the twenty-first century are more independent, have acquired greater control over their bodies and can decide when and how many children they wish to have (Orloff, 1996). However, when they become pregnant they develop a strong dependence on the healthcare system: technology and the presence and input of health professionals become indispensable features in order to reduce the anxiety provoked by the perceived lack of confidence in their ability as mothers (Georgsson Öhman et al., 2007). The women in our study mainly wish to feel protected, understood and accompanied in motherhood.

The role assigned to patients in relation to health professionals has also changed in recent years. The paternalistic model has been abandoned and patient autonomy has gained increasing importance. Furthermore, these changes have occurred in parallel with an improvement in the cultural and academic status of women, as well as the development of new communication technologies that enable greater access to health information (Anderson et al., 2003). Taken together these features have led health professionals to adopt an imminently informative model of healthcare (Burke, 1980; Veatch, 1975). This model is based on a clear distinction between facts and values (Emanuel and Emanuel, 1990). However, as we have seen in this study, women, both during pregnancy and especially when giving birth, believe their feelings and values should be understood by professionals, from whom they seek empathy and a personal commitment, and not just information. Women feel vulnerable during pregnancy and the birth process, and wish to be comforted and be able to develop a real relationship of trust (Cooke, 2005). This should lead us toward a more shared model of healthcare (Emanuel and Emanuel, 1990; Charles et al., 1999), one in which the professional-user relationship is established within a framework that enables a 
commitment to be made to moral deliberation. A vital component in this process is the promotion of the interpersonal and communication skills of the care providers.

However, in addition to the communicative and ethical skills of the professionals, the structural aspects of care are particularly important. Proctor,1998; identified the influence of the environment or the location and access to the centres where services are provided as vital in the perception of the quality of care.

An interesting aspect in the use of the new technologies is the popularity of ultrasound scanning during pregnancy, which is considered and perceived as if it were a consumer item. Some authors have questioned the use of ultrasound during pregnancy for non-diagnostic purposes (Chevernak and McCullogh, 2005) as the use of the foetal image for non-medical reasons fosters the medicalization of pregnancy. Others have also argued that the progressive medicalization of pregnancy and antenatal care has lessened women's control over their own pregnancies (Narotzky, 1995). For the women in our study, seeing the image of their future child enabled them to satisfy both their curiosity and, at the same time, their need for objective evidence of the foetus' presence and well-being. They were not comfortable with relying solely on their own abilities to perceive the baby inside them; only being able to hear the foetal heartbeat and, especially, see the ultrasound image were able to reassure them that the foetus was alive and doing well. We live in an age governed by images and the women needed this image to feel reassured and less anxious. Rothman, 1986; refers to this situation as a tentative pregnancy, in that many women, who have come to undervalue their own perceptions, end up experiencing their pregnancy according to the views of health professionals. This idea is confirmed by our study, in which most of the women expressed a strong dependency on health professionals and technology. 


\section{References:}

Anderson, J., Rainey, M., Eysenbach, G., 2003. The impact of CyberHealthcare on the physician-patient relationship. Journal of Medical Systems 27, 67-84.

Aristotle, (384-322 b.C), 1994. Ética a Nicomano. Pub. Universidad de Valencia, Valencia.

Bardin, L., 1986. Análisis de contenido. Akal, Madrid.

Barlow, Y., 1994. Childbirth: Management of Labour Through the Ages, Nursing Time $35,40-43$.

Beauchamp, T.L., Childress, J. F., 1994. Principles of Biomedical Ethics. (4 $4^{a}$ ed.). Oxford University Press, New York.

Belle-Brown, J., Beckhoff, C., Bickford, J., Stewart, M., Freeman, T.R., Kaspersi, M.J., 2009. Women and their partner's perceptions of the key roles of the labor and delivery nurse. Clinical Nursing Research 18, 323-335.

Burke, G., 1980. Ethics and medical decision-making. Primary Care 7, 615-624.

Cabero, L., 2003. Tratado de Ginecología, Obstetricia y Medicina de la Reproducción. Tomo I. Editorial Médica Panamericana, Madrid.

Carrera, J.M., Gallo, M., López, M., 2001. Aspectos legales del diagnostico prenatal. Diagnóstico prenatal de los defectos congénitos. In Fabre, E., (Ed.), Manual de asistencia al embarazo normal. Fabre, Zaragoza. pp. 446-454.

Charles, C., Gafni, A., Whelan, T., 1999. Decision making in the professional-patient encounter: revisiting the shared treatment decision making model. Social, Science \& Medicine 49, 651-665.

Chevernak, F.A., McCullogh, L.B., 2005. An ethical critique of boutique fetal imaging: A case for the medicalization of fetal imaging. American Journal of Obstetrics and Gynecology 192, 31-33.

Collière, M., 1982. Promouvoir la vie. InterEditions, Paris. 
Cooke, P., 2005. Helping Women to Make their own Decisions in Raynor MD, Marshall JE, Sullivan A, (Eds.), Decision Making in Midwifery Practice. Elsevier: Churchill Livingstone, Edinburgh/ New York. pp. 127-142.

Declerq, E.R., Sakala, C., Corry, M.P., Appelbaum, S., 2006. Listening to Mothers II: Report of the Second National U.S. Survey of Women's Childbearing Experiences. Childbirth Connection, New York.

Defensor del Pueblo España., 2007. Informe anual 2006. Oficina del Defensor del Pueblo, Madrid.

Department of Health., 1993. Changing Childbirth, Vol. 1. Her majesty's Stationery Office, London.

Emanuel, E.J., Emanuel, L.L., 1990. Cuatro modelos de la relación médico-paciente. In Cruceiro A. (Ed.), Bioética para clínicos. Triacastela, Madrid. pp. 109-126.

Fawcett, J., Pollio, N., Tully, A., 1992. Women's perceptions of caesarean and vaginal delivery: another look. Research in Nursing and Health 15, 439-446.

Fowles, E.R., 1998. Labour concerns of women two months after delivery. Birth 25, 235-240.

García Martínez, M., 2008. History of art in childbirth in family environment [Spanish]. Cultura Cuidados 12, 40-47.

Georgsson Öhman, S., Grunewald, C., Waldenström, U., 2009. Perception of risk in relation to ultrasound screening for Down's syndrome during pregnancy. Midwifery 25, 264-276.

Green, J.M., 1993. Expectations and experiences of pain in labour: findings from a large prospective study. Birth 20, 65-72.

Guba E.G., Lincoln, Y.S., 1989. Fourth generation evaluation: NewBury Park, California, Sage. 
Hammersley, M., Atkinson, P., 2001. El diseño de la investigación; problemas, casos y muestras, Etnografía. In: M. Hammersley and P. Atkinson, (Eds), Métodos de la Investigación, Paidos, Barcelona. pp. 40-68.

Janssen, B.M., Wiegers, T.A., 2006. Strengths and weaknesses of midwifery care from the perspective of women. Evidence Based Midwifery 4, 53-59.

Jimenez, V., Klein, M.C., Hivon, M., Mason, C., 2010. A Mirage of Change: FamilyCentered Maternity Care in Practice. Birth 37, 160-167.

Johanson, R., Newburn, M., Macfarlane, A., 2002. Has the medicalisation of childbirth gone too far? BMJ 324, 892-895.

Johnson, M., Smith, J., Haddad, S., Walker, J., Wong, A., 1992. Women prefer hospital births (letter). BMJ 305: 255.

Jonas, H., 1995. El principio de responsabilidad. Ensayo de una ética para la civilización tecnológica. Harder, Barcelona.

Kippendroff, K., 1980. Metodología del análisis del contenido. Paidos, Barcelona.

Kitzinger, S., 1992. Childbirth and Society. In Chalmers, I., Enkin, M., Keirse, M.J.N.C. (Eds.), Effective Care in Pregnancy and Childbirth. Oxford University Press, Oxford/New York/Toronto. pp. 99-109.

Kornelsen, J., 2005. Essences and imperatives: An investigation of technology in childbirth. Social, Science \& Medicine 61, 1495-1504.

Krueger, R.A. Casey, M.A., 2000. Focus groups :a practical guide for applied research, 3rd edn. Sage Publications, Thousand Oaks Calif.

Kukla, R., 2009. Finding autonomy in birth. Bioethics 23, 1-8.

Lavender, T., Walkinshaw, S.A., Walton, I., 1999. A prospective study of women's views of factors contributing to a positive birth experience. Midwifery 15, 40-46. 
Lavender, T. Hofmeyr, G.J., Neilson, J.P., Kingdon, C., Gyte, C., 2004. Caesarean section for non medical reasons at term (Protocol for a Cochrane Review). In The Cochrane Library, Issue 2, Chichester, UK: John Wiley \& Sons.

Larkin, P., Begley, C.M., Devane, D., 2009. Women's experiences of labour and birth: an evolutionary concept analysis. Midwifery 25, e-49, e-59.

Maroto-Navarro, G., García-Calvente, M. M., Mateo-Rodríguez, I., 2004. El reto de la maternidad en Espanya: dificultades sociales y sanitarias. Gaceta Sanitaria 18(Sup 2), 13-23.

Marquez, S., Meneu, R., 2003. La Medicalización de la vida y sus protagonistas. Gestión clínica y Sanitaria 5, 47-53.

McKinlay, J. B., 1982. From "promising report" to "Standard procedure": Seven stages in the career of a medical innovation. In Milbank Reader. (Eds), Technology and the Future of Health Care. MIT Press, Cambridge, Vol. 8. pp.233-270.

Ministerio de Sanidad y Consumo., 2006. Plan de Calidad para el Sistema Nacional de Salud. Ministerio de Sanidad y Consumo, Madrid.

Narotzky, S., 1995. Mujer, mujeres, género. Consejo Superior de Investigaciones científicas, Madrid.

Observatorio de Salud de la Mujer y del Sistema Nacional de Salud., 2007. Estrategia de Atención al Parto Normal. Ministerio de Sanidad y Consumo, Madrid.

Orloff, A., 1996. Gender in the welfare state. Annual Review of Sociology 22, 51-78.

Petra, G., Marlene, C. M., Abbas, S. T., 2004. Factors related to childbirth satisfaction. Journal of Advanced Nursing 46, 212-219.

Proctor, S., 1998. What Determines Quality in Maternity Care? Comparing the Perceptions of Childbearing Women and Midwives. Birth 25, 85-93.

Redshaw, M., 2008. Women as Consumers of Maternity Care: Measuring "Satisfaction" or "Dissatisfaction"? Birth 35, 73-76. 
Rothman, B. K., 1986. The Tentative Pregnancy: Prenatal Diagnosis and the Future of Motherhood. Viking, Nueva York.

Sabaté, S., Gomar, C., Canet, J., Fernández, C., Fernández, M., Fuentes, A., 2006. Obstetric anaesthesia in catalonia, Spain. Medicina Clínica 126 Suppl 2, 40-45.

Slade, P., MacPherson, S.A., Hume, A., Maresh, M., 1993. Expectations, experiences and satisfaction with labor. The British Journal of Clinical Psychology 32, 469-483.

Smeenk, A.D., ten Have, H.A., 2003. Medicalization and obstetric care: an analysis of developments Dutch midwifery. Medicine, Health Care, and Philosophy 6, 153-165.

Strauss, R.P., 2002. Beyond easy answers: prenatal diagnosis and counselling during pregnancy. The Cleft Palate - Craniofacial Journal 39, 164-168.

Taylor, S.J., Bogdan, R., 1998. Introducción a los métodos cualitativos de Investigación (4⿳亠丷厂 ed.), Paidos, Barcelona.

Thompson, C., 2010. Sure Start Children's Centers: time to make them better known. The journal of family health care $20,45-47$.

Vandenvusse, L., 1999. Decision making in analyses of women's birth stories. Birth 26, 43-50.

Van Maanen, M., 1990. Researching lived experience: human science for an action sensitive pedagogy. Abany, NY, State University of New York Press.

Veatch, R.M., 1975. Models for ethical medicine in a revolutionary age. Hasting Centre Report 2, 3-5.

Von Wrigth, G.H., 1987. Explicación y comprensión. Alianza Universidad, Madrid.

Wade, D.T., Halligan, P.W., 2004. Do biomedical models of illness make for good healthcare systems? BMJ 329, 1398-1401.

Waldenstrom, U., 1996. Modern maternity care: does safety have to take the meaning out of birth? Midwifery 12, 165-173. 
Weber, R., 1990. Basic Content Analysis. Sage, London.

Wiegers, T.A., 2009. The quality of maternity care services as experienced by women in the Hetherlands. BMC pregnancy Childbirth 9,18.

Williams, C., 2006. Dilemmas in fetal medicine: premature application of technology or responding to women's choice. Sociology of Health and IIIness 28,1-20.

Young, D., 2009. What is normal childbirth and do we need more statements about it? Birth 36, 1. 
Acknowledgments,

Our acknowledgment to all the women who voluntarily participated in the focus groups, also to de supervisors of Women's Sexual and Reproductive Health Programme for facilitating our work. 
TABLE 1

First focus group Cornellà

\begin{tabular}{|c|c|c|c|c|}
\hline & AGE & Na OF BIRTH & DELIVERY & HOSPITAL \\
\hline 1 & 25 & 1 & Normal & Public institution \\
\hline 2 & 32 & 2 & Normal & Public Institution \\
\hline 3 & 35 & 2 & Normal & Private Centre \\
\hline 4 & 27 & 1 & Forceps & Public Institution \\
\hline 5 & 33 & 1 & Caesarean & Private Centre \\
\hline 6 & 28 & 2 & Normal & Public Institution \\
\hline 7 & 30 & 1 & Normal & Public Institution \\
\hline 8 & 30 & 1 & Forceps & Public Institution \\
\hline
\end{tabular}

TABLE 2

Second focus group Cornellà

\begin{tabular}{|c|c|c|c|c|}
\hline & AGE & No OF BIRTH & DELIVERY & HOSPITAL \\
\hline 1 & 32 & 1 & Normal & Public institution \\
\hline 2 & 32 & 1 & Caesarean & Public Institution \\
\hline 3 & 29 & 1 & Normal & Private Centre \\
\hline 4 & 30 & 1 & Caesarean & Public Institution \\
\hline 5 & 33 & 2 & Normal & Public Institution \\
\hline 6 & 31 & 1 & Normal & Private Centre \\
\hline 7 & 27 & 1 & Spatulas & Public Institution \\
\hline 8 & 32 & 2 & Normal & Public Institution \\
\hline 9 & 28 & 1 & Normal & Public Institution \\
\hline
\end{tabular}

TABLE 3

Third focus group Cornellà

\begin{tabular}{|c|c|c|c|c|}
\hline & AGE & Na OF BIRTH & DELIVERY & HOSPITAL \\
\hline 1 & 29 & 1 & Forceps & Public institution \\
\hline 2 & 30 & 1 & Normal & Public Institution \\
\hline 3 & 28 & 1 & Spatulas & Public Institution \\
\hline 4 & 28 & 1 & Normal & Public Institution \\
\hline 5 & 31 & 1 & Normal & Public Institution \\
\hline
\end{tabular}

TABLE 4

Focus group Centelles

\begin{tabular}{|c|c|c|c|c|}
\hline & AGE & No OF BIRTH & DELIVERY & HOSPITAL \\
\hline 1 & 27 & 1 & Normal & Public institution \\
\hline 2 & 31 & 1 & Normal & Public Institution \\
\hline 3 & 31 & 1 & Normal & Public Institution \\
\hline 4 & 30 & 1 & Caesarean & Public Institution \\
\hline 5 & 34 & 2 & Spatulas & Public Institution \\
\hline
\end{tabular}


TABLE 5

Focus group Vic

\begin{tabular}{|c|c|c|c|c|}
\hline & AGE & No OF BIRTH & DELIVERY & HOSPITAL \\
\hline 1 & 33 & 1 & Normal & Public institution \\
\hline 2 & 29 & 1 & Caesarean & Public Institution \\
\hline 3 & 27 & 1 & Spatulas & Public Institution \\
\hline 4 & 24 & 1 & Normal & Public Institution \\
\hline
\end{tabular}

